\title{
New Cooling System Design of BLDC Motor for Electric Vehicle Using Computation Fluid Dynamics Modeling
}

\author{
Duc Thuan Vu and Pyung Hwang* ${ }^{\dagger}$ \\ Department of Mechanical Engineering, Yeungnam University \\ *School of Mechanical Engineering, Yeungnam University \\ (Received May 2, 2013 ; Revised July 18, 2013 ; Accepted July 23, 2013)
}

\begin{abstract}
Overheating in electrical motors results in detrimental effects such as degradation of the insulation materials, demagnetization of magnets, increases in Joule losses, and decreases in motor efficiency and lifetime. Thus, it is important to find ways to dissipate heat from the motor and to keep the motor operating at its most efficient temperature. In this study, a new design to guide air flow through a given brushless direct current (BLDC) motor is developed and the design is analyzed, specifically by using computational fluid dynamics (CFD) simulations. The results showed that the temperature distribution in the three proposed models is lower than that in the original model, although the speed of the cooling fan in the original model reaches a very high value of $15 \times 10^{3} \mathrm{rpm}$. The results also showed that CFD can be effectively used to simulate the heat transfer of BLDC motors.
\end{abstract}

Keywords - brushless direct current motor, hybrid electric vehicles, numerical method, cooling systems, computational fluid dynamics

\section{Introduction}

Brushless direct current (BLDC) motors are increasingly being employed in electrical vehicles (EVs) and hybrid electric vehicles because of their high efficiency, high power density, and minimal maintenance [1]. The ability of a BLDC motor to function as a generator during regenerative braking makes it ideal for application to EVs.

The motor temperature is closely linked to the life and performance of BLDC motors. The stator winding temperature directly affects the durability of the winding insulation system, whereas the rotor temperature affects the efficiency of the permanent magnet [2]. Overheating in the windings increases Joule losses because the electrical resistance of the winding material is highly temperature dependent [2]. Therefore, it is

†Corresponding author : phwang@yu.ac.kr

(a) 이 논문은 한국윤활학회 2013년도 춘계학술대회(2013 4. 26. 서울테크노파크) 발표논문임. imperative to conduct thermal analyses in the design of BLDC motors. Heat generated within an electric motor comes from two primary sources: electromagnetic losses and mechanical losses. Electromagnetic losses consist of Joule losses attributable to the flow of electric current and core losses attributable to the hysteresis effect. Mechanical losses compose of bearing frictional losses and windage losses [3].

Most recent publications have focused on cooling system designs that use water, in which a water jacket is usually located between the stator frame and the stator core [4-7]. According to the flow path of cooling water, a water jacket can be classified into two categories: circumferential water jacket and axial water jacket. For the circumferential water jacket, the cooling water flows along the spiral-type path from one end of the stator frame to the other and removes the heat from the machine. For the axial water jacket, the plates are mounted on the surface of the stator to form many axial paths, which are connected together. The cooling water 
flows along the axial direction of the machine from one side to the other [5]. However, both structures have disadvantages such as a more complicated manufacturing process and the necessity of a water pump for the water jacket to drive the cooling water flows in channels.

To prevent the temperature of the winding from rising, the unidirectional ventilated motor has been studied [8-10]. The cooling airflows enter the motor from one end and exit from the other end in an axial direction. Consequently, the windings and iron core are cooled directly with external air and the overall temperature of the motor decreases significantly. Nevertheless, this method also has some drawbacks; for instance, the windings and other inside parts are not protected from moisture and dust, which may affect durability and the overall performance of the motor [11].

In this study, adaptive methods to guide air flow through a given BLDC motor are developed and the methods are analyzed, specifically by solving both the heat transfer and fluid dynamics problems, particularly the important factors such as the optimal shape and dimensions of air guide casings to ensure the best aerodynamic characteristics of flow in the channel. As a result, the thermal efficiency is increased as much as possible.

\section{BLDC Motor and Proposed Cooling System}

\section{2-1. BLDC Motor}

The $1.2 \mathrm{~kW}$ BLDC motor in a car air-conditioning

Table 1. Specifications of analyzed motor

\begin{tabular}{cc}
\hline \hline Parameter and dimensions & Value \\
\hline Number of slots & 12 \\
\hline Number of poles & 4 \\
\hline Rated power & $1.2(\mathrm{~kW})$ \\
\hline Rated speed & $8,000(\mathrm{rpm})$ \\
\hline Air gap length & $0.4(\mathrm{~mm})$ \\
\hline Permanent magnet & Nd-IPM $[1.2 \mathrm{~T}]$ \\
\hline
\end{tabular}

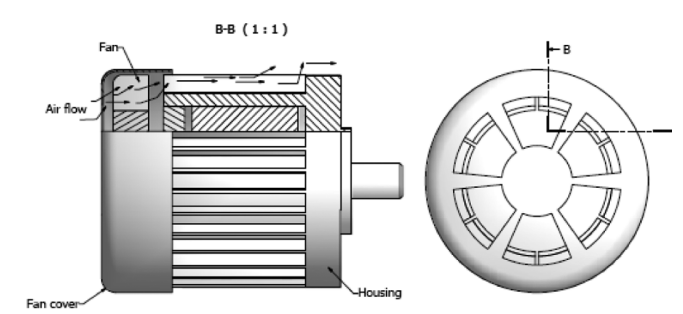

motor.

Fig. 1. Prototype of BLDC motor.

system with a cooling fan is shown in Fig. 1, and the corresponding specifications are tabulated in Table 1.

Fig. 1 shows front and side views of the analyzed motor. Air enters through the opening slots on the fan cover, passes through the fan, and enters the housing. The rotor, stator, windings, and insulation are totally enclosed to protect them from moisture and dust, which affect the durability and overall performance of the motor.

\section{2-2. Structure of proposed cooling system}

2-2-1. Case 1: Cooling of motor fins

To clarify the influence of internal aerodynamics on the cooling system, a simple case of an air guide casing is introduced, as shown in Fig. 2. In this case, the cooling air flows along the axial direction from one end of the cooling fins to the other and removes the heat from the motor.

2-2-2. Case 2: Cooling of motor housing surfaces

For case 1, some parts of the motor (for instance, the back cover of the motor) seem to be unaffected by the air flow through the motor. As a result, a new design method is presented to improve the cooling efficiency of the motor. This is shown in Fig. 3. In this case, the

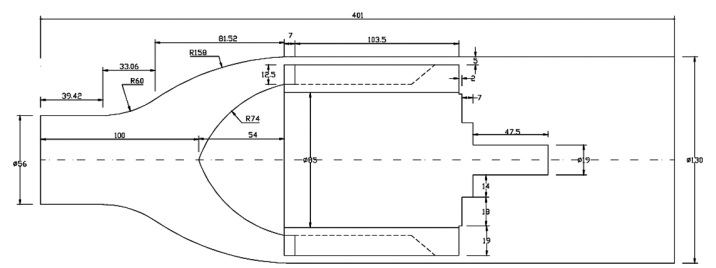

Fig. 2. Structure of cooling system for motor fins. 


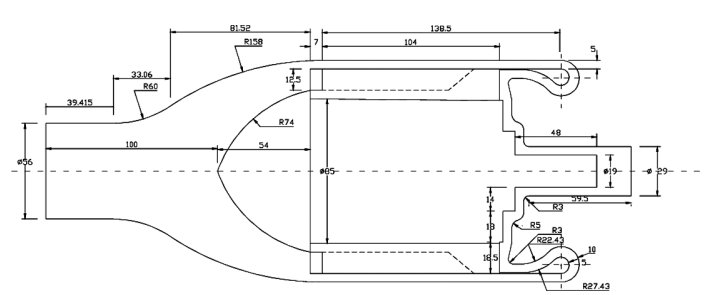

Fig. 3. Structure of cooling system for motor housing surfaces.

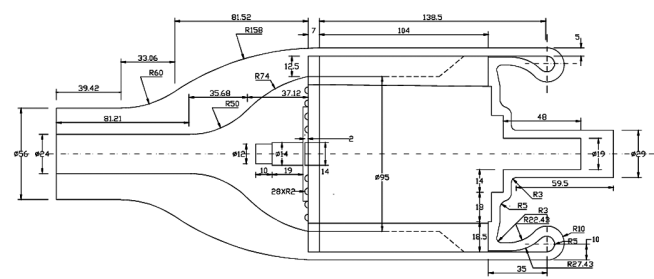

(a) Technical drawing

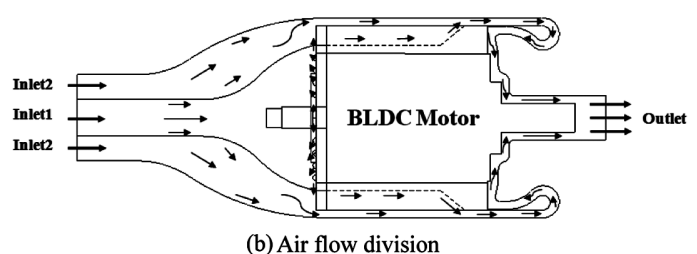

Fig. 4. Structure of cooling system for complete outer surface of motor.

cooling air is guided to the rear of the motor housing and the back cover is directly cooled with external air. Consequently, the overall temperature of the motor decreases significantly.

2-2-3. Case 3: Cooling of outer surfaces of the motor

To obtain the highest cooling efficiency for a given motor, the proper method to guide cooling air flow through the entire outer surface of the motor is implemented by separating inflow into two parts so that the front cover is also cooled as much as possible. Fig. 4 describes the structure of the cooling system for the complete outer surface of the motor.

\section{CFD Model Formulation}

\section{3-1. Grid model}

To solve discrete equations in the finite volume method, first, the grid model is generated by ANSYS

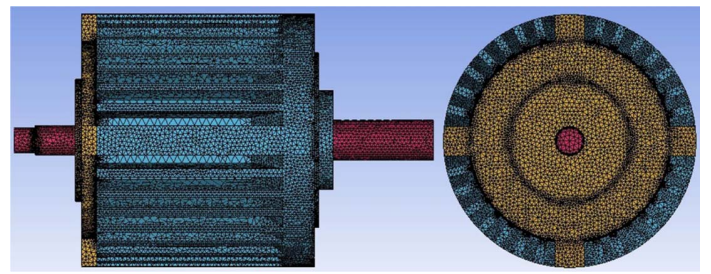

Fig. 5. Grid model.

ICEM CFD [12]. A tetrahedral mesh is created relatively easily by using smart functions, curvatures, proximity etc., with high mesh quality (more than 0.3 ). Furthermore, controlling the density of the mesh according to problem requirements is also considered here, for example, for the regions in which the flow direction is changed significantly. Hence, the entire mesh is divided into approximately 1.5 million cells, as shown in Fig. 5.

\section{3-2. Boundary conditions}

The boundary conditions used for solving the heat transfer problem on the BLDC motor are as follows. For the inlet, the boundary condition in terms of velocity is used here, corresponding to each case of the inlet velocity. For the outlet, the pressure boundary condition with atmospheric pressure is set. Additionally, the remaining boundaries are set to a solid wall. Thus, the casing walls, except the boundary walls of the secondary flow in cases of new design methods, are assumed to be insulation walls and other walls are set up with specific values of temperature, which were obtained from calculations using ePhysics software [13].

\section{3-3. Solution method}

The air flow through a motor is simulated by solving governing equations describing the properties of flow. For this, the continuity equation and the NavierStokes equations [14], commonly used in the computational fluid dynamics (CFD) method, are the basic equations, as shown below:

$$
\frac{\partial \rho}{\partial t}+\frac{\partial}{\partial x_{j}}\left(\rho u_{j}\right)=0
$$

$$
\frac{\partial \rho u_{i}}{\partial t}+\frac{\partial}{\partial x_{j}}\left(\rho u_{i} u_{j}\right)=-\frac{\partial p}{\partial x_{i}}+\frac{\partial}{\partial x_{j}}\left[\mu_{e f f}\left(\frac{\partial u_{i}}{\partial x}+\frac{\partial u_{j}}{\partial x_{i}}\right)\right]
$$


In addition, to consider the heat transfer between the surfaces of the motor and moving air flow in contact with the surfaces, the relative energy equations need to be activated. The heat transfer problem addressing forced convection is solved under adaptive boundary conditions for heat walls (see section 2.2 for more details). The convective heat transfer equation [14] is as follows:

$$
q=h_{f}\left(T_{W}-T_{f}\right)+q_{r a d}
$$

Here, $h_{f}$ denotes the fluid-side local heat transfer coefficient, $T_{w}$ and $T_{f}$ are the wall surface temperature and local fluid temperature, respectively, and $q_{r a d}$ is the radiative heat flux.

\section{Results and Discussion}

\section{4-1. Original BLDC model}

Some surface regions of the motor, such as half of a fin side or the back cover, seem to not be cooled, as shown in Fig. 6. This is also one of the drawbacks when a fan is used to cool the motor. Although the speed of the cooling fan reaches a very high value, the temperature on the housing surface is still high: 345.2 $\mathrm{K}$ at $15 \times 10^{3} \mathrm{rpm}$.

\section{4-2. Proposed cooling models}

4-2-1. Case 1

In case 1 , motor fins are cooled by cooling air through it with a lower temperature $(300 \mathrm{~K})$. The results are presented in Figs. 7 to 9. By using this method, the average temperature on the fins is signif-

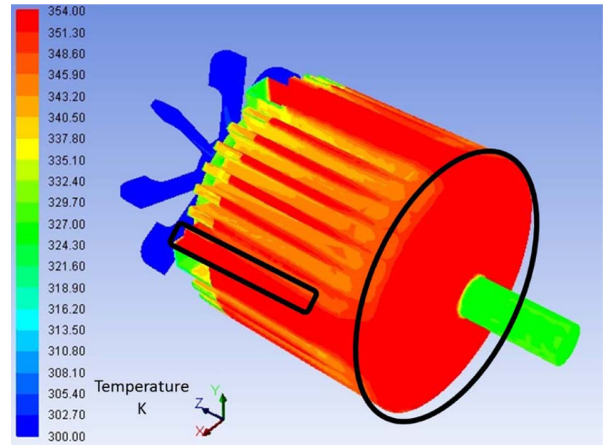

Fig. 6. Contour of temperature distribution on motor housing surfaces.

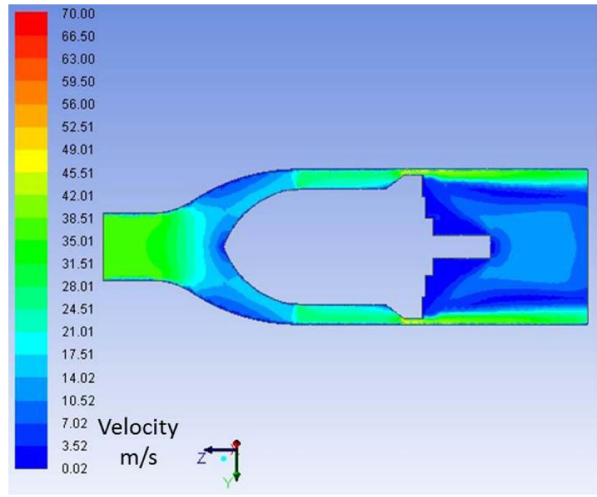

Fig. 7. Contour of velocity distribution.

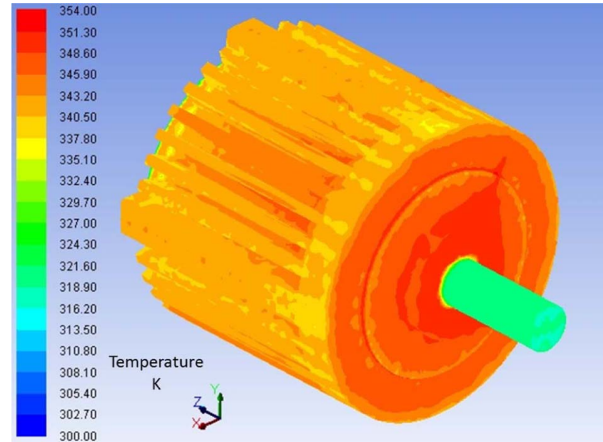

Fig. 8. Contour of temperature distribution on motor fins.

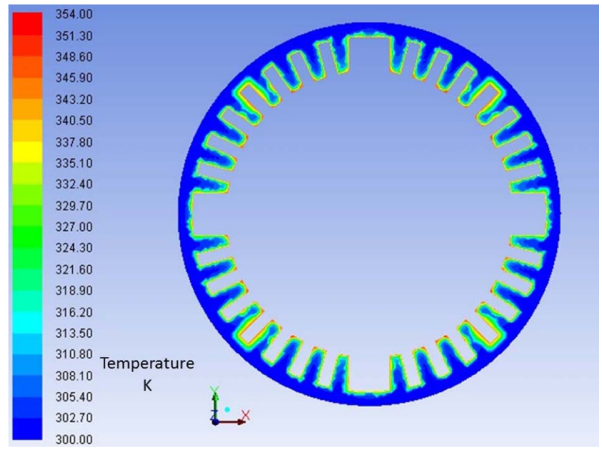

Fig. 9. Contour of temperature distribution on $Z$ plane.

icantly reduced, from 353.506 to $342.587 \mathrm{~K}$, in proportion to an inlet velocity of $35.805 \mathrm{~m} / \mathrm{s}$. Additionally, all of the fin surfaces are cooled and a vortex region with hydraulic loss can be created, which is apparently not detected in most domains, except for one near to the outlet of the model. This is one reason that case 2 is 


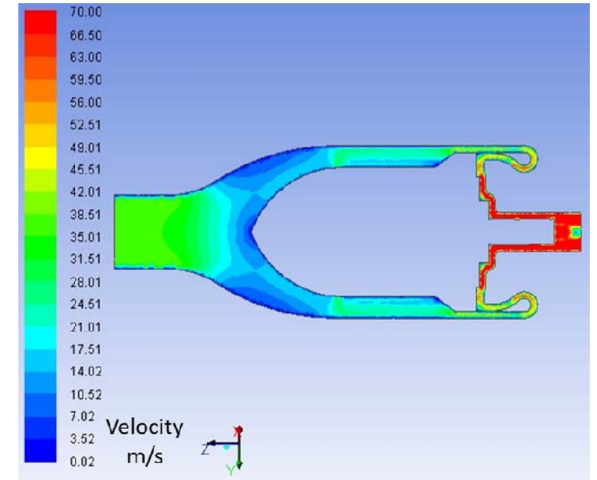

Fig. 10. Contour of velocity distribution.

introduced in the next section.

\section{4-2-2. Case 2}

A special design for cooling all the surfaces of the motor housing is developed to improve the cooling efficiency of forced convection and to minimize the hydraulic loss in the system. Hence, the back cover and back shaft included are clearly cooled, as shown by the blue and green regions in Fig. 11. Because air velocity through this region is so high, either the heat transfer rate or carrying heat increases significantly.

\section{4-2-3. Case 3}

Case 3 is similar to case 2; however, the air guide casing is redesigned including the front cover of the motor so that the previous design is not changed and the new design favorably affects the final results. Some of these results are shown in Figs. 12 to 14.

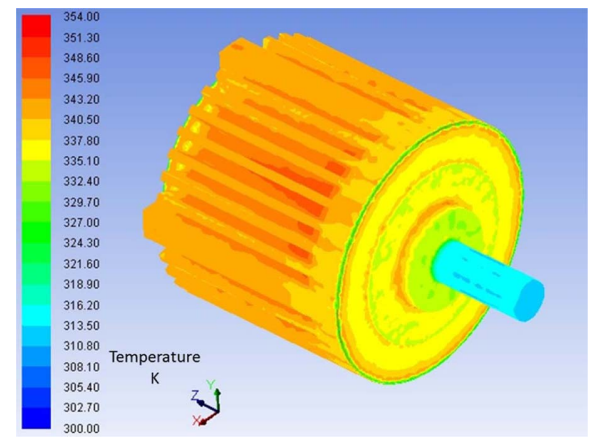

Fig. 11. Contour of temperature distribution on motor housing surfaces.

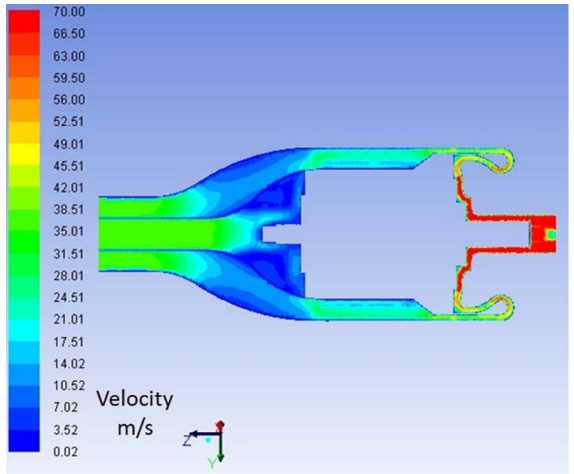

Fig. 12. Contour of velocity distribution.

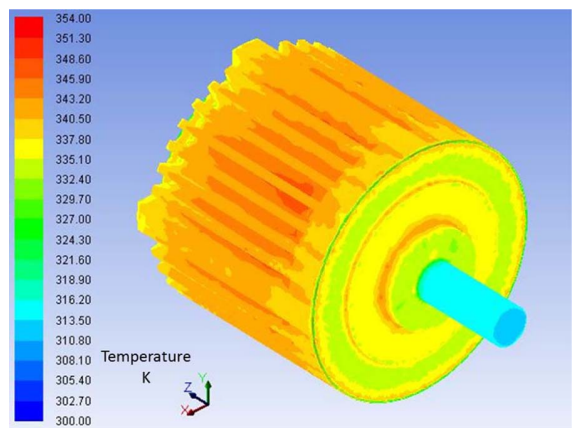

Fig. 13. Contour of temperature distribution on housing surfaces.

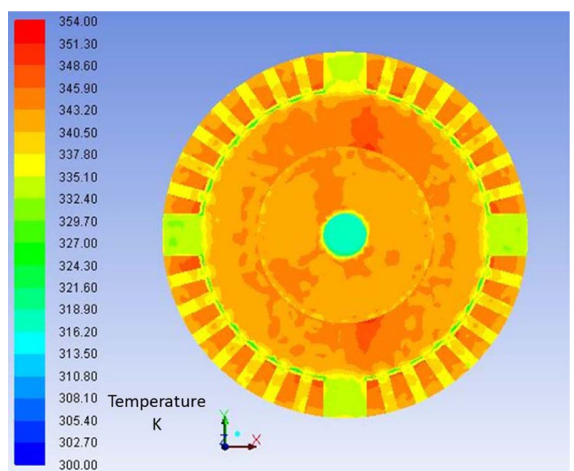

Fig. 14. Contour of temperature distribution on front cover.

The variation of the specific quantities related to heat transfer with respect to velocity is shown in Fig. 15.

In Fig. 15, the mean temperature obtained in the motor decreases from case 1 to case 3 , corresponding to the different design methods of the air guide casing. These three cases are significantly lower than the original case of the BLDC model. The temperature in 


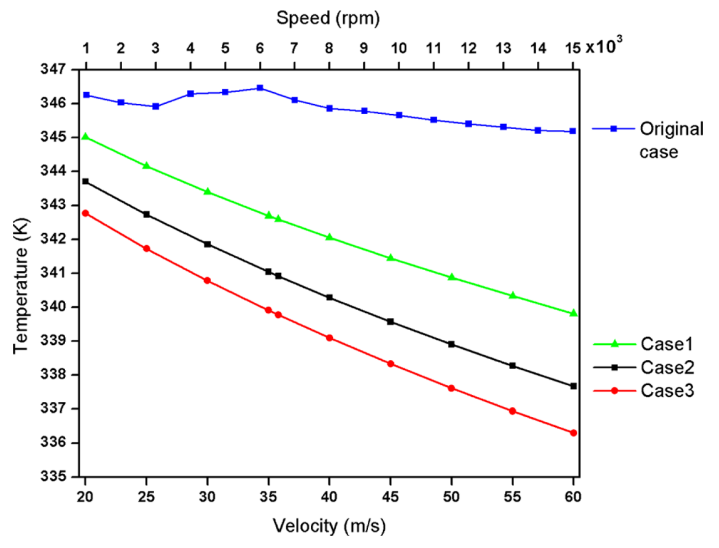

Fig. 15. Variation of temperature versus velocity and cooling fan speed.

cases 2 and 3 is decreased much more than in case 1, up to $2.14 \mathrm{~K}$. Furthermore, for case 3 , the front cover of the motor is also cooled apparently well (see Fig. 14). This means that the entire outer surfaces of the motor were efficiently cooled.

\section{Conclusions}

The cooling system of a BLDC motor was investigated by adaptive design methods addressing the effects of internal aerodynamics. Thus, the cooling efficiency obtained from the proposed methods is significantly higher than the original efficiency. Thus, these results can be used as reference materials in motor design and manufacture. In addition, to further increase the cooling efficiency for this system, new approaches such as the design of a proper cooling fan based on the proposed methods will continue to be studied in the future.

\section{Acknowledgment}

This research was funded by Yeungnam University.

\section{References}

1. Jang, S. M., Cho, H., and Choi, S. K., "Design and Analysis of High-Speed Brushless DC Motor for Centrifugal Compressor," IEEE Transaction on Magnet- ics, Vol. 43, pp. 2573-2575, 2007.

2. Liao, C., Chen, L., and Katcher, T., "Thermal Management of Ac Induction Motor Using Computational Fluid Dynamics Modeling," Institute of Electrical and Electronics Engineers, IEEE, pp. 189-191, 1999.

3. Kuria, J. and Hwang, P., "Optimizing Heat Sink Geometry for BLDC PM Motor for Electric Vehicle Using CFD," Sustainable Research and Innovation Conference, May, 2011.

4. Fan, J. X., Zhang, C. N., Wang, Z. F. ,and Strangas, E. G., "Thermal Analysis of Water Cooled Surface Mount Permanent Magnet Electric Motor for Electric Vehicle," Electrical Machines and Systems (ICEMS), IEEE International Conference, 2010.

5. Tong, W., Tang, R., An, Z. L., and Shen, Q., "Water Cooling System Design and Thermal Analysis for Low Speed Permanent Magnet Machines," Electrical Machines and Systems (ICEMS), IEEE International Conference, 2011.

6. Song, L., Li, Z., Gao, J., Zeng, Q. C., and Wang, F., "3D Thermal Analysis of Water Cooling Induction Motor used for HEV," Electrical Machines and Systems (ICEMS), IEEE International Conference, 2008.

7. Ye, Z. N., Luo, W. D., Zhang, W. M., and Feng, Z. X., "Simulative Analysis of Traction Motor Cooling System Based on CFD," Electric Information and Control Engineering (ICECE), IEEE International Conference, 2011.

8. Takafumi, N., Kasumi, S., Shozo, H., Fuminori, I., and Masami, H., "Cooling Airflow in Unidirectional Ventilated Open-Type Motor for Electric Vehicles," IEEE Transactions on Energy Conversion, Vol. 21, No. 3, September 2006.

9. Tong, W., Wu, S., An, Z. L., Zhang, H., and Tang, R., "Cooling System Design and Thermal Analysis of Multibrid Permanent Magnet Wind Generator," International Conference on Electrical and Control Engineering, 2011.

10. Zhang, Y., Ruan, J., Huang, T., Yang, X., Zhu, H., and Yang, G., "Calculation of Temperature Rise in Air Cooled Induction Motors Through 3-D Coupled Electromagnetic Fluid-Dynamical and Thermal FiniteElement Analysis," IEEE Transactions on Magnetics, Vol. 48, No. 2, February 2012.

11. Branch, F. E., "Keeping Motor Windings Dry," Facilities Engineering Branch, Denver Office, Denver, Colorado, 1991.

12. ANSYS, ICEM CFD User's Manual, Version 13, 2010.

13. Vu, D. T. and Hwang, P., "Thermal Analysis of BLDC Motor for air conditioning system," KSTLE conference, Seoul, South of Korea, April, 2012.

14. ANSYS, FLUENT User's Manual, Version 13, 2010. 